\title{
Design Requirement and DC Bias Analysis on HVDC Converter Transformer
}

\author{
Weijian Peng ${ }^{1, *}$, Qi Liu ${ }^{2}$, Li Liang ${ }^{3}$, Wenqi Jiang ${ }^{4}$, Zhuoyuan Zhang ${ }^{5}$ \\ 1,2,3,4,5 UNSW, School of Electrical Engineering and Telecommunications, Sydney, Australia
}

\begin{abstract}
The converter transformer plays a critical role in the high-voltage direct current (HVDC) transmission system, which connects but separates the AC grids and the converter. This paper briefly introduced the essential design requirement of the HVDC converter transformer in a system at $\pm 800 \mathrm{kV}$ level and analyzed the DC bias influence on the transformer. The DC bias current effect simulations are analyzed in MATLAB and ANSYS Maxwell in this paper, respectively.
\end{abstract}

\section{Introduction}

The development of high-voltage power transmission is an inevitable requirement for the power industry to develop to a particular stage. Compared with AC transmission, the high-voltage direct current (HVDC) transmission has the characteristics of large transmission power capacity, small loss, long transmission distance, and good flexibility to connect two unsynchronized systems.[1] The high-voltage converter transformer is one of the critical equipment of an HVDC system. Hence, defining the design requirement and analyzing the highvoltage converter transformer's unique feature is crucial.[2]

The line-commuted converter (LCC)-based HVDC system has been widely used in many projects for many years[3], while the voltage source converter (VSC)based HVDC transmission system is more prevalent in recent years[4]. For these two typical systems, the converter transformer plays a role in the converter station structure as connecting the $\mathrm{AC}$ grids to the $\mathrm{DC}$ transmission lines at both sending and receiving ends (Figure 1.). Moreover, there are thyristors, harmonic filters, smoothing reactors, and much other equipment in the converter station[5], which should be seriously considered in designing a converter transformer.

One of the converter transformers' significant functions in the LCC-based HVDC transmission system is providing a 30 degrees phase shift for two 6-pulse rectifiers to connect as one 12-pulse rectifier[6]. The converter transformer will also insulate the DC part and the AC system from each other to avoid direct shortcircuiting caused by the neutral point grounding of the $\mathrm{AC}$ system and the neutral point grounding of the DC part[7].

Similar to the ordinary transformer in the low-voltage grids, the basic structure with specific parameters such as the rated currents, voltages, and the minimal shortcircuit impedance of the converter transformer should be calculated[8]. Moreover, due to the nonlinear operation characteristic of the converter in the HVDC system, losses, vibration and the harmonic noise in the system[9-11], and some electromagnetic vibrations of their windings and cores of itself[12-14], the operation of the converter transformer will be affected. Hence, these vibrations and noises may lead to some engineering projects' operation failures [15]. Besides, in the actual operation, if the topology of the system only uses one pole at an end which forms the circuit with the ground, the DC bias current will flow through the neutral point and pour into the windings, which contributes a lot to the undesirable vibration[16]. An overview of the DC bias current was given[17], but it has not calculated the DC component's value in a specific system. Paper [18] provides the simulation in both $2 \mathrm{D}$ and $3 \mathrm{D}$ of the transformer's electromagnetic response using the fieldcircuit coupling[18]. However, it has not combined with the insulating materials and has not analyzed the DC bias effect in the actual operation. Hence, a 3-dimension electric field simulation was proposed[19], but it has not considered the DC bias current either.

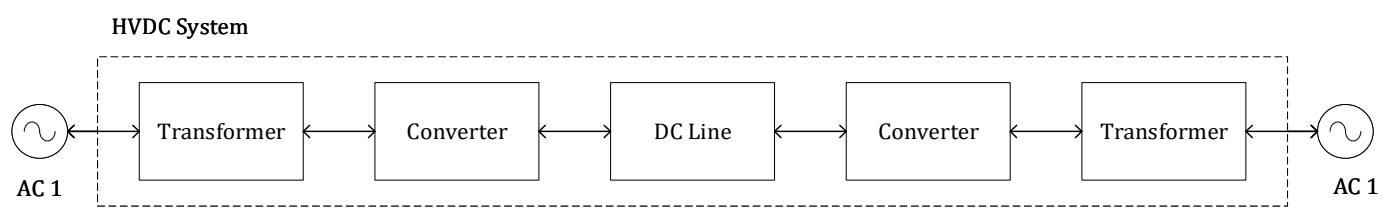

Figure 1. The HVDC System

\footnotetext{
* Corresponding author: weijian.peng@student.unsw.edu.au
} 


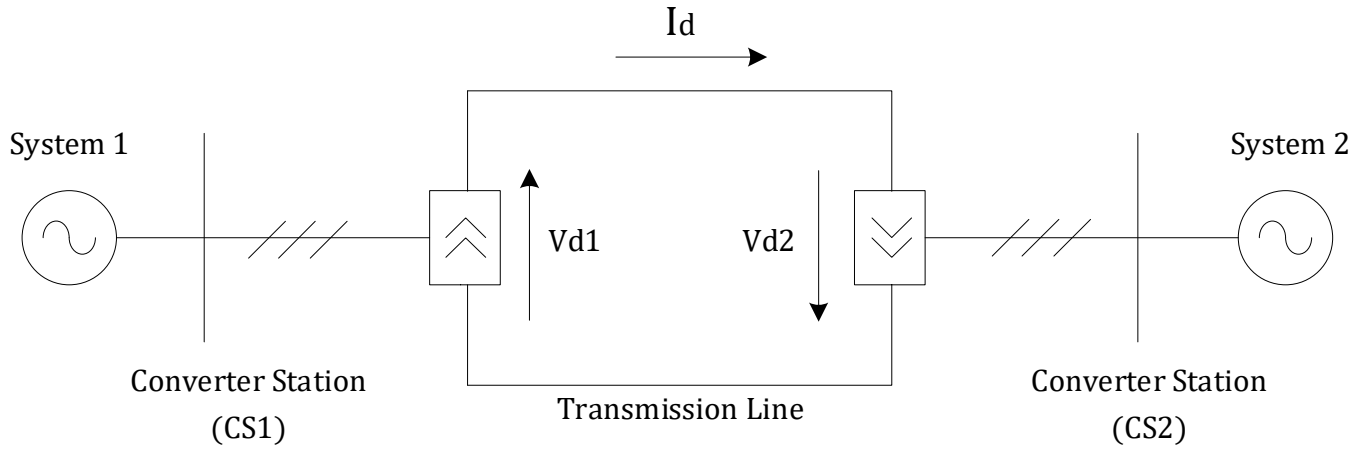

Figure 2: The Structure of the HVDC Transmission System

Therefore, the purpose of this article is to find the basic design requirements and the DC bias influence on the HVDC converter transformer based on hypothetical long-distance DC transmission projects. This paper is organized as follows. The second chapter defines the system structure and the topology, also gives the data of the system. Based on the second chapter's data, the basic design requirements are shown in chapter III. Aiming at the high-voltage converter transformer's no-load simplified circuit model, a 2D and 3D simulation analysis of the DC bias problem is carried out respectively in chapter IV. The simulation results are compared in the final part.

\section{HVDC Transmission System Structure and Parameters}

The converter transformer in this essay is based on an HVDC system, the voltage level of which is $\pm 800 \mathrm{kV}$ with $5000 \mathrm{MW}$ capacity in the $1373 \mathrm{~km}$ long overhead transmission line. To calculate the converter transformer's basic parameters and get on further analysis, the structure and fundamental parameters of the transmission system in both stable and unstable working state must be known.

\subsection{System Structure and Wiring Configuration}

As shown in Figure 2, the HVDC transmission system is composed of an overhead transmission line and two converter stations which can complete the mutual conversion between AC and DC. Typically, when AC system 1 provides the power to AC system 2, the second converter station is the inverter station. When Vd1 is bigger than $\mathrm{Vd} 2$, the current will flow in the direction shown in Figure 2. Note that only when the converter station works in the converter state and $\mathrm{Vd} 2$ is bigger than Vd1 will the energy transfer from ACI to ACII.

\subsection{Converter Station and Its Main Equipment}

The converter station is the core part of the HVDC transmission system that includes some leading equipment: the converter bridge, converter transformer, smoothing reactors, the Static Var Compensators (SVCs), and the AC and DC filters. The station also has a set of lightning arrestors, circuit breakers, current transformers (CTs), voltage transformers (VTs), high-frequency blockers, and ground devices. The converter station structure in more detail is shown in figure 3.

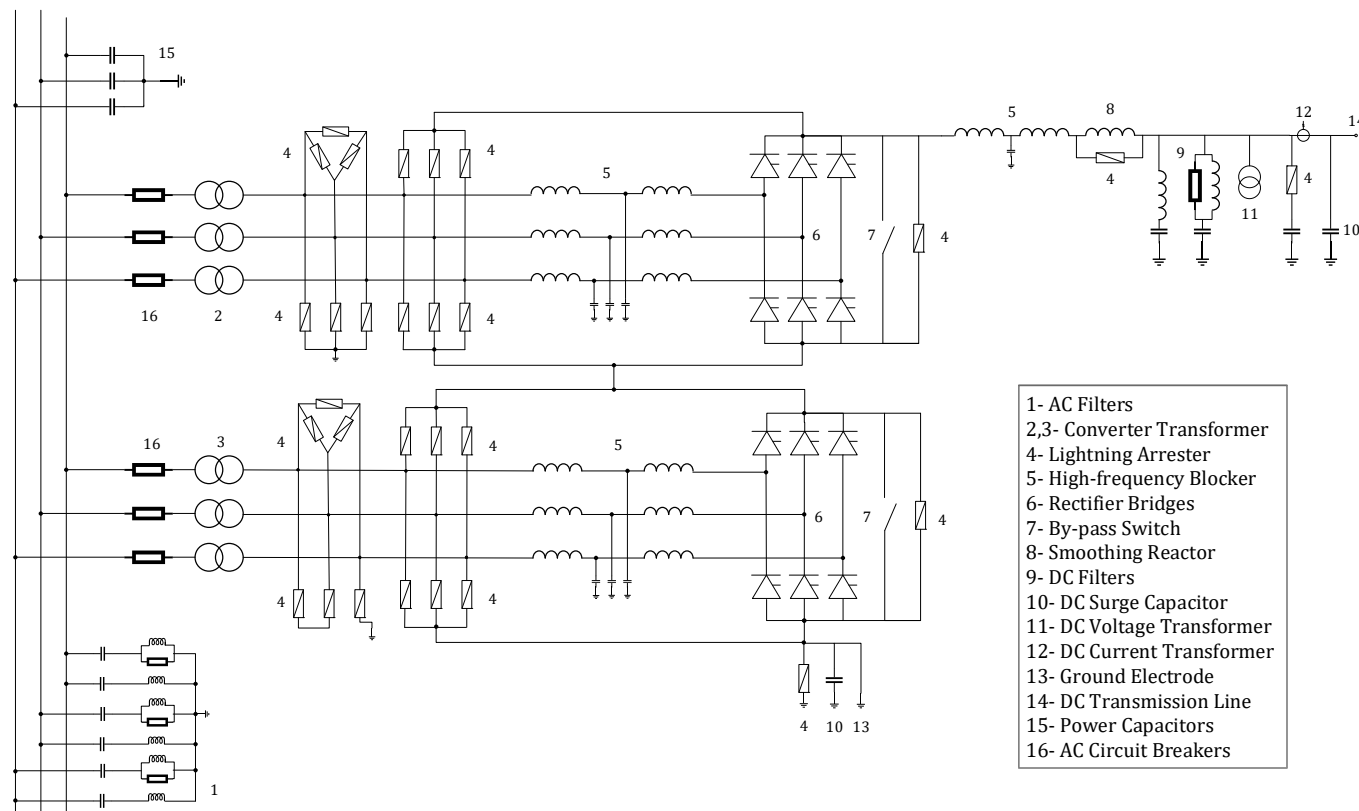

Figure 3: The Converter Station Structure 
In the HVDC transmission system, the set of converters is one of the essential devices which normally use the fully controlled three-phase bridge converter circuit as the basic unit to converter the $\mathrm{AC}$ energy to DC energy. In this essay, the double 12-pulse rectifier bridge circuit is used as the basic converter unit.

At the converter station, the "pole" is defined as the DC terminal in the same polarity. Each pole as the station has two double 12-pulse rectifier bridge circuits in series. Each double 12-pulse rectifier bridge circuit comprises two single 6-pulse rectifier bridge circuits in series, one of two called high-voltage valve and the other one called low-voltage valve. Hence, for the bipolar neutral wiring method, there are two poles with eight single 6-pulse rectifier bridge circuits totally, which is shown in Figure 4.

\subsection{The Parameters of the System}

The required electrical parameters of the HVDC transmission system refer to the ability that the system can work stably in the long run and are the basis of subsequent engineering design with high reliability and efficient economy. The parameters such as rating current and rating voltage at both steady and transient states should be considered to quantify the delivery capacity of the system and for accurate design of the devices in this system. The system parameters are shown in Table 1.

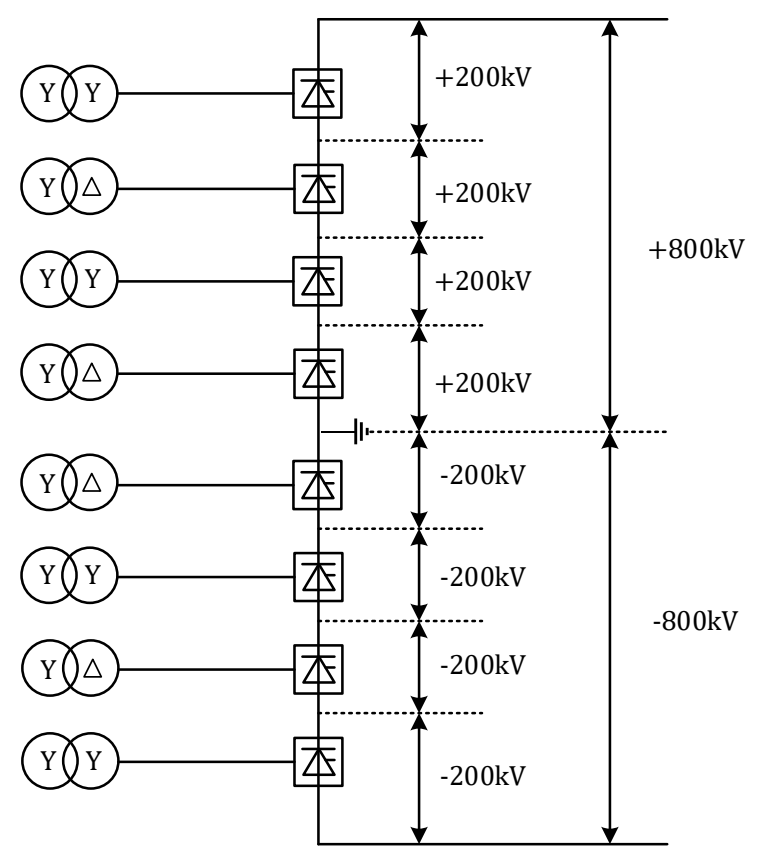

Figure 4: The Pole Structure at Converter Station
Table 1: Parameters of the HVDC Transmission System

\begin{tabular}{|c|c|c|}
\hline Item & $\begin{array}{c}\text { Rectifier } \\
\text { side }\end{array}$ & $\begin{array}{c}\text { Inverter } \\
\text { side }\end{array}$ \\
\hline $\begin{array}{c}\text { Rinimum power } \\
\text { (Pmin/MW) }\end{array}$ & \multicolumn{2}{|c|}{5000} \\
\hline Rated DC current (IdN/A) & \multicolumn{2}{|c|}{3125} \\
\hline $\begin{array}{c}\text { Rated DC voltage } \\
\text { (UdN/kV) }\end{array}$ & \multicolumn{2}{|c|}{ $\pm 800 / \pm$} \\
\hline $\begin{array}{c}\text { Overhead line economical } \\
\text { rated voltage/kV }\end{array}$ & \multicolumn{2}{|c|}{765.819} \\
\hline $\begin{array}{c}\text { DC step-down operating } \\
\text { voltage (80\%) Ur1/kV }\end{array}$ & \multicolumn{2}{|c|}{640} \\
\hline $\begin{array}{c}\text { DC step-down operating } \\
\text { voltage (70\%) Ur2/kV }\end{array}$ & 560 \\
\hline $\begin{array}{c}\text { Rated trigger delay Angle } \\
\text { (a) }\end{array}$ & 15 & - \\
\hline Rated extinction angle (Y) & - & 18.7 \\
\hline $\begin{array}{c}\text { Single-phase double } \\
\text { winding inverter capacity/ } \\
\text { (MVA) }\end{array}$ & 250.21 & 244 \\
\hline $\begin{array}{c}\text { Inverter short-circuit } \\
\text { impedance /\% }\end{array}$ & 18 & 18.5 \\
\hline $\begin{array}{c}\text { The rated line voltage of } \\
\text { the inverter network side } \\
\text { winding/kV }\end{array}$ & 525 & 525 \\
\hline $\begin{array}{c}\text { The rated line voltage of } \\
\text { the inverter valve side } \\
\text { winding/kV }\end{array}$ & 169.9 & 169.9 \\
\hline Inverter tap switch series \\
\hline $\begin{array}{c}\text { Distance between the tap } \\
\text { changer/\% }\end{array}$ & $18 /-6$ & $16 /-8$ \\
\hline
\end{tabular}

\section{The Basic Design Requirement of the Converter Transformer}

According to the system's voltage level with such a capacity and the specific type of converter bridge circuit, which is given in chapter 2 , a converter transformer with proper short-circuit impedance, lower loss, and stable and reliable operation needs to be designed. The size of the core and the tank, and the cooling system are also critical for the design work. Firstly, the basic structure and the parameters of the converter transformer are designed in this chapter.

\subsection{Core}

The core is the converter transformer's primary component, which forms the magnetic circuit to realize the transformation between electric energy and magnetic energy, due to the effect of DC bias current, which may periodically saturate the core, significantly increasing the loss and temperature rise of the transformer. Therefore, 


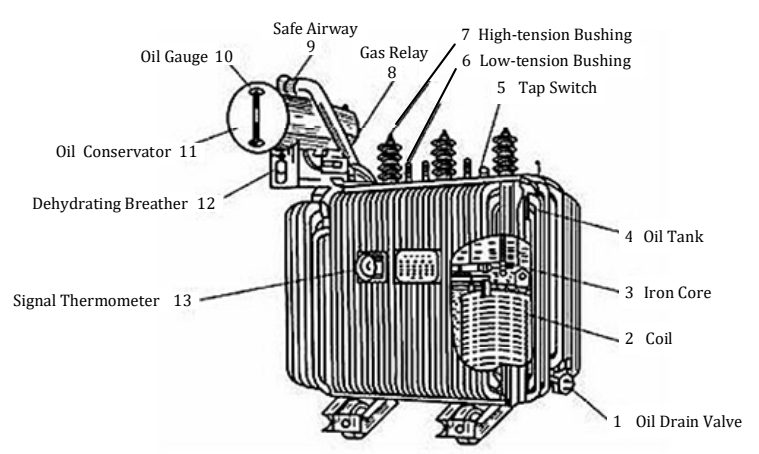

Figure 5: The Components of the Transformer

the converter transformer's core must have good antisaturation capability and low loss characteristics.

Silicon steel with high magnetic permeability is a commonly used core material at present. It is usually laminated with cold-rolled silicon steel sheets with a thickness of $0.35-0.55 \mathrm{~mm}$, effectively reducing eddy current loss and hysteresis loss, and is very suitable for the DC bias research. The cross-section of the core column generally uses a stepped type in HVDC transmission. Also, a larger diameter core is used to leave cooling oil channels between the laminations to facilitate heat dissipation.

\subsection{Windings}

The single-phase two-winding transformers play a critical role in connecting the AC source and the rectifier bridges. Every three converter transformers provide 3 phases voltage respectively to a single 6-pulse rectifier bridge. Therefore, 12 single-phase two-winding transformers are needed in this design.

The windings of the converter transformer here are the same as the typical AC high voltage transformer. However, to obtain the 12-pulse waveform, the input voltage of the high-voltage valve and the low-voltage valve should have a $30^{\circ}$ degree difference. Usually, the wiring method of the windings of these 3 single-phase

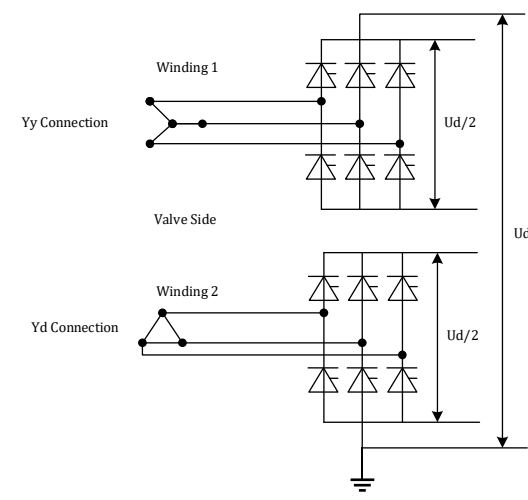

Figure 6: The Winding Connection Method of the Transformer

two-winding transformers, which connect to the highvoltage valve, is star connection. In contrast, the transformers which relate to the low-voltage valve are delta connection.

This article adopts the most commonly used transformer wiring method in the current HVDC transmission system, the 12-pulse rectifier bridge method. Specifically, each 6-pulse rectifier bridge circuit is connected in series to the $\mathrm{AC}$ side power grid through $\mathrm{Yy}$ and $\mathrm{Yd}$ winding transformers. The converter transformer provides the two 6-pulse converters, the high-voltage valve-side converter unit and the lowvoltage valve-side converter unit, with a phase difference of $30^{\circ}$, thereby forming a 12-pulse rectifier bridge structure. Suppose the winding method of the converter transformers is all the same (both in Yy winding method or Yd winding method ). In that case, the phase angle of the $\mathrm{AC}$ voltage of the 6-pulse converter remains equal, and the output rectified voltage has the same waveform and amplitude. The combined output is unable to produce 12-pulse output voltage and unable to reduce AC side harmonics (especially the 5th and 7th harmonics), which affects the regular operation of the HVDC system.

The Fourier series of the current of the high-voltage valve-side converter transformer (Yy winding) can be expanded as:

$$
\mathrm{i}_{6 \mathrm{~A}}=2 \times \frac{\sqrt{3}}{\pi} \times\left(\sin \omega t+\frac{1}{5} \sin 5 \omega t+\frac{1}{7} \sin 7 \omega t+\frac{1}{11} \sin 11 \omega t+\frac{1}{13} \sin 13 \omega t+\frac{1}{17} \sin 17 \omega t+\frac{1}{19} \sin 5 \omega t\right)
$$

And the Fourier series of the current of the lowvoltage valve-side converter transformer ( $\mathrm{Yd}$ winding) $i_{6 B}$ can be expanded as same as Equation (1). Hence, the
Fourier series of the current of the low-voltage valveside converter transformer ( $\mathrm{Yd}$ winding) can be developed as:

$$
\mathrm{i}_{12}=\mathrm{i}_{6 \mathrm{~A}}+\mathrm{i}_{6 \mathrm{~B}}=4 \times \frac{\sqrt{3}}{\pi} \times\left(\sin \omega t+\frac{1}{5} \sin 5 \omega t+\frac{1}{7} \sin 7 \omega t+\frac{1}{11} \sin 11 \omega t+\frac{1}{13} \sin 13 \omega t+\ldots\right)
$$

It can be seen that the 5th, 7th, 17th, and 19th harmonics generated by the two 6-pulse rectifier circuits cancel each other out, and only the $12 \mathrm{k} \pm 1$ th harmonic is injected into the $\mathrm{AC}$ valve side that is, $11,13,23,25$, and other harmonics.

\subsection{Tank and Cooling System}

This article selects oil-immersed transformers for discussion and analysis. An oil-immersed transformer is that the body of the transformer is installed in an oil tank filled with insulating oil, which can strengthen insulation and improve cooling and heat dissipation. The oil tank is 
welded with steel plates and has an oval shape. To facilitate heat dissipation, a flat tube type radiator is installed on the tank's wall, which can save oil in the same heat dissipation area compared to the round tube type. The oil conservator's function is to reduce the contact surface between the transformer oil and the air, slow down the oxidation of the transformer oil and absorb moisture, thereby slowing down the deterioration of the oil.

The radiator expands the transformer oil through the heat generated during the operation of the transformer. When there is a temperature difference between the upper oil temperature and the lower oil temperature of the transformer, the cooler forms oil temperature convection, which flows back to the oil tank after being cooled by the cooler to reduce the temperature of the transformer. In large high-voltage transformers, internal oil pumps will be installed to speed up heat dissipation by forced oil circulation. To enhance cooling, two electric fans are installed under each radiator for auxiliary heat dissipation.

\subsection{Short-circuit Impedance Calculation}

The increase of short-circuit impedance can significantly reduce harmonics and reduce the harmonic losses of converter transformers and filters. However, the converter transformer's reactive power loss is positively related to the short-circuit impedance of the converter transformer. The more significant the short-circuit impedance, the greater the reactive power loss, and the required reactive power compensation costs will increase accordingly. So from an economic point of view, the smaller the short-circuit impedance of the converter transformer, the lower the overall price of the converter station. Therefore, in designing the short-circuit impedance of the converter transformer, it is necessary to minimize the short-circuit impedance while meeting the maximum short-circuit current limit. It can be seen that the calculation of short-circuit impedance is important in transformer design and HVDC system design.

The formula for calculating the short-circuit impedance of the converter transformer is:

$$
u_{k}=\frac{2 I_{d}}{\mathrm{I}_{M}}-\frac{S_{n}}{S_{M}}
$$

Where $I_{d}$ is the rated DC current; $S_{n}$ is the rated capacity of the single-phase converter transformer; $S_{M}$ is the maximum short-circuit capacity. And the basic parameters that need to calculate the short-circuit impedance in the system design are shown in Table 2 below.

Table 2: Parameters to Calculate the Short-circuit Impedance

\begin{tabular}{|c|c|}
\hline Basic Parameters & Values \\
\hline Rated DC Current /A & 3125 \\
\hline Rated DC Voltage/kV & $\pm 800 / \pm 400$ \\
\hline
\end{tabular}

\begin{tabular}{|c|c|} 
Rating Power /MVA & 250.21 \\
\hline $\begin{array}{c}\text { Maximum Short-circuit } \\
\text { Current of AC Side/kA }\end{array}$ & 33 \\
\hline $\begin{array}{c}\text { Inrush current of converter } \\
\text { valve } / \mathrm{kA}\end{array}$ & 38 \\
\hline
\end{tabular}

Therefore,

$$
S_{M}=3 \times 800 \times 33=79200 M V A
$$

Combined with Equation (3), the short-circuit impedance is calculated by Equation (4).

$u_{k}=\frac{2 I_{d}}{\mathrm{I}_{M}}-\frac{S_{n}}{S_{M}}=\frac{2 \times 3.125}{33}-\frac{250.21}{79200}=0.186=18.6 \%$

\section{DC Bias Analysis}

\subsection{D Model in MATLAB Simulink}

DC bias is an abnormal working state of the transformer because the equivalent impedance of the transformer's primary side only shows resistance characteristics to the DC component. The internal resistance of the primary winding is minimal. Therefore, a tiny DC component will form a large DC magnetizing potential in the winding, which acts on the primary side of the transformer together with the AC magnetic potential. The DC component biases the transformer core, causing the transformer core's working magnetization curve to shift, causing a part of the original magnetization curve working area to move to the core magnetic saturation area, and asymmetry about the origin appears. As a result, the total excitation current occurs in a peak wave. This is the so-called transformer bias phenomenon.

There are two main reasons for the DC bias of the transformer in the HVDC system. Firstly, the solar plasma wind's dynamic change interacts with the geomagnetic field to produce a geomagnetic storm. The change of the geomagnetic field induces a potential gradient on the earth's surface, and the potential ground gradient generates a low frequency induced current in the transformer windings. Secondly, when the DC transmission system uses the earth as the return mode of single-stage operation, the earth becomes a part of the DC circuit, and all the current delivered by the DC is transmitted through the earth. Therefore, a potential difference is formed between the two grounding electrodes, and the potential difference generates a direct current. The direct current flows into the transformer winding through the transformer's neutral point, thereby causing a DC bias phenomenon.

The DC bias will bring the following hazards to the converter transformer in the HVDC system:

1. Increase the reactive power loss of the transformer.

2. Cause the malfunction of the protection relay.

3. The high saturation of the iron core increases the magnetic leakage and causes the overheating of the components.

4. Local overheating causes the paper insulation to age and decompose the transformer oil, which affects the transformer's life. 
5. The vibration and noise of the transformer are significantly increased.

The usual measures to suppress DC bias include:

1. Install a DC voltage source at the transformer's neutral point or set up a degaussing coil in the key transformer to generate a compensation current that flows into the neutral point in the opposite direction.

2. Connect a series resistance at the neutral point of the transformer to limit the magnitude of the DC.

3. Connect a series of capacitance compensation on the transformer winding outlet line to block the DC path.

When using SIMULINK in MATLAB to simulate DC bias's influence on the transformer, there are generally two ways to add the DC component to the transformer. The first one is to connect a standard AC voltage power supply to the primary side of the transformer. The DC component will be injected from the secondary side in direct current, that is, in the form of a direct current source. The second one is to make the standard sinusoidal voltage source and the DC voltage source connected in series, which are applied on the same side of the transformer as the excitation and injected in the form of DC voltage.

The excitation current can be seen from the simulation Figure 7 with different DC source voltage. When the transformer is usually working (i.e., when DC source $=0 \mathrm{~V}$ ), the excitation current waveform is a normal sinusoidal waveform. When the DC component is added to the transformer, the excitation current waveform is distorted due to the transformer's core saturation, and burrs appear in the waveform. The larger the DC component, the more serious the excitation current distortion.

As shown in Figure 8, when the excitation current is distorted, the current on the secondary side will also change accordingly. There will be protrusions in the waveform, which will affect the normal operation of the system. If the protrusions are too large, it will also affect the malfunction of the relay.
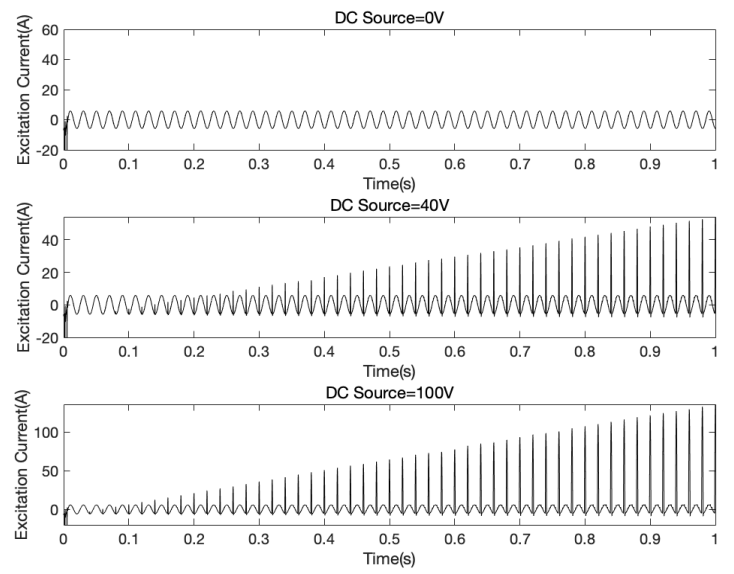

Figure 7: The Excitation current

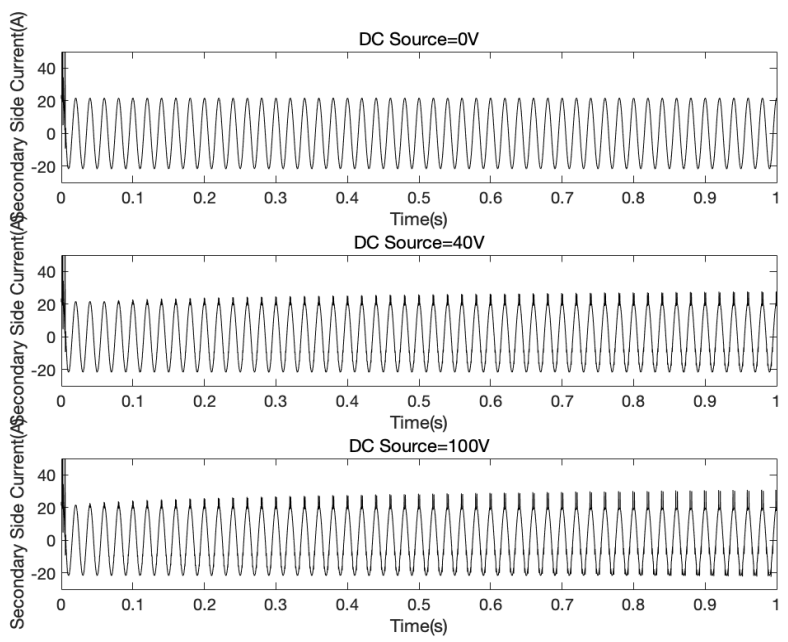

Figure 8: The Secondary Side current

\subsection{D Model in ANSYS Maxwell}

The DC bias current that flows in through the windings will also increase the magnetic flux density of the iron core or even reach saturation. The core of the converter transformer is the main loop of the magnitude flux. To analyse the core state with DC bias, ANSYS Maxwell, excellent electromagnetic simulation software that can create a 3D model, was used to simulate the transformer's operation. In this part, the magnetic flux density is mainly studied. 
The model this essay established has been reasonably simplified. The voltage rating is scaled down in volts scale. The tank, cooling system, and other devices are ignored. Then the 3D model of the three-phase threecolumn transformer can be seen in Figure 10. At the normal operation, the excitation current, voltages of the primary and the secondary side, current of the secondary side, and the magnitude density distribution figures are shown in Figure 12.

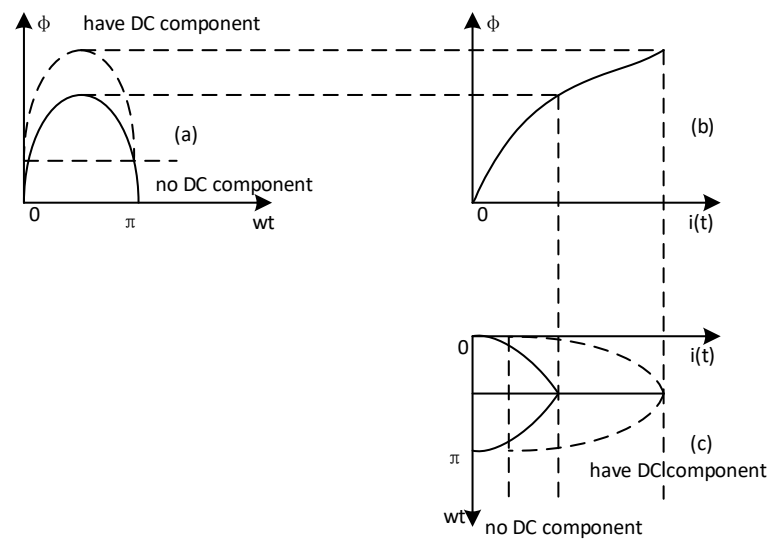

Figure 9: The effect of DC bias on the core

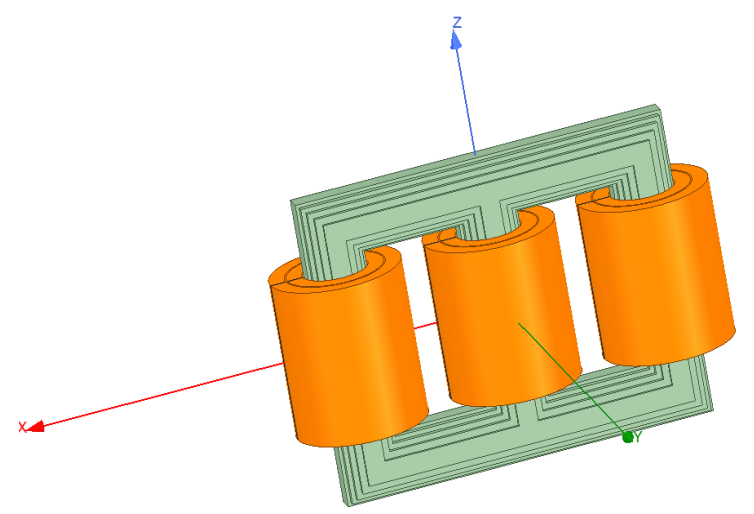

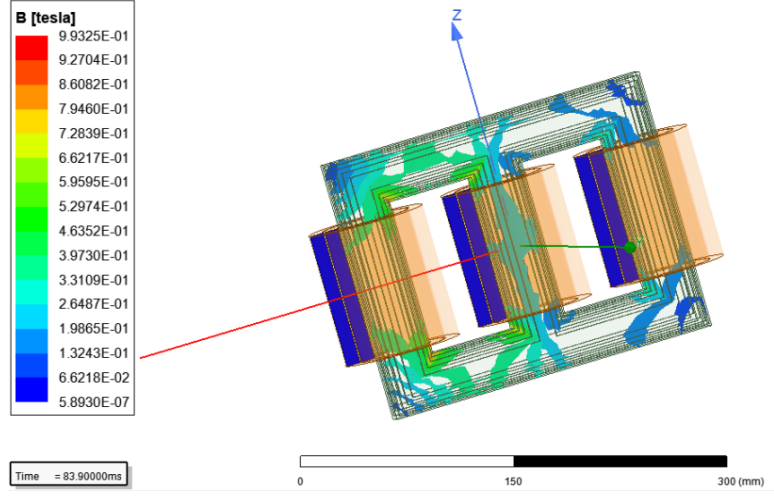

Figure 11: The Magnitude Density Distribution at Normal operation

These figures above show that the model this essay established is correct, i.e., the excitation current curve is standard. Because the secondary is equivalent to be open-loop, so the current is very small. The magnitude flux density distribution can be seen in Figure 11. In this figure, the rendered blue part indicates that the magnetic flux density is relatively low, and the red region shows that the magnetic flux density is rather large. In a normal operating state, the transformer core's magnetic flux density is generally about 1 Tesla.

When the 5V DC voltage is added to the winding, the new magnitude flux density distribution can be seen in Figure 13(a). In this figure, the maximum flux density is increased. When $10 \mathrm{~V}$ and $40 \mathrm{~V}$ DC voltages are injected into the windings at the primary side, the maximum flux density increases by degrees.

Figure 10: 3D Model of the Converter Transformer

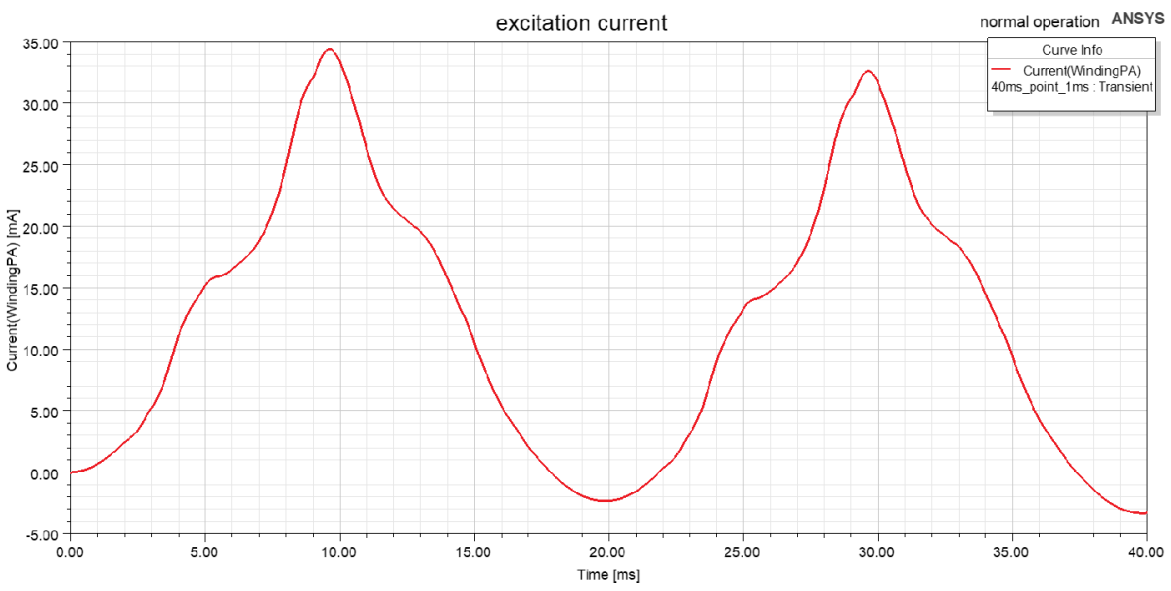

(a) Excitation current in phase A. 


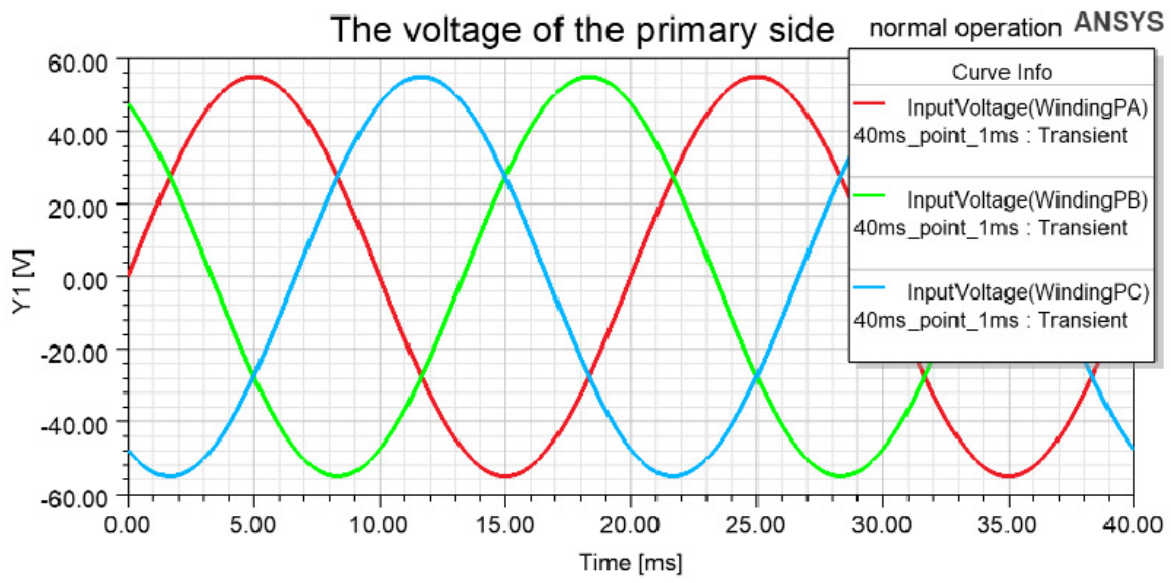

(b) The voltage of the primary side.

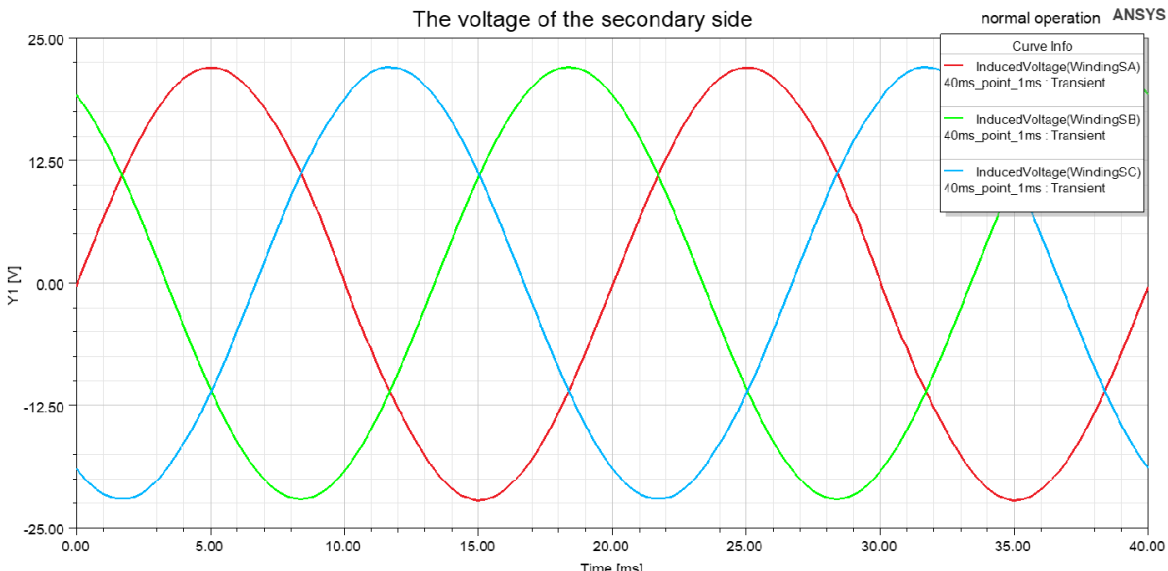

(c) The voltage of the secondary side.

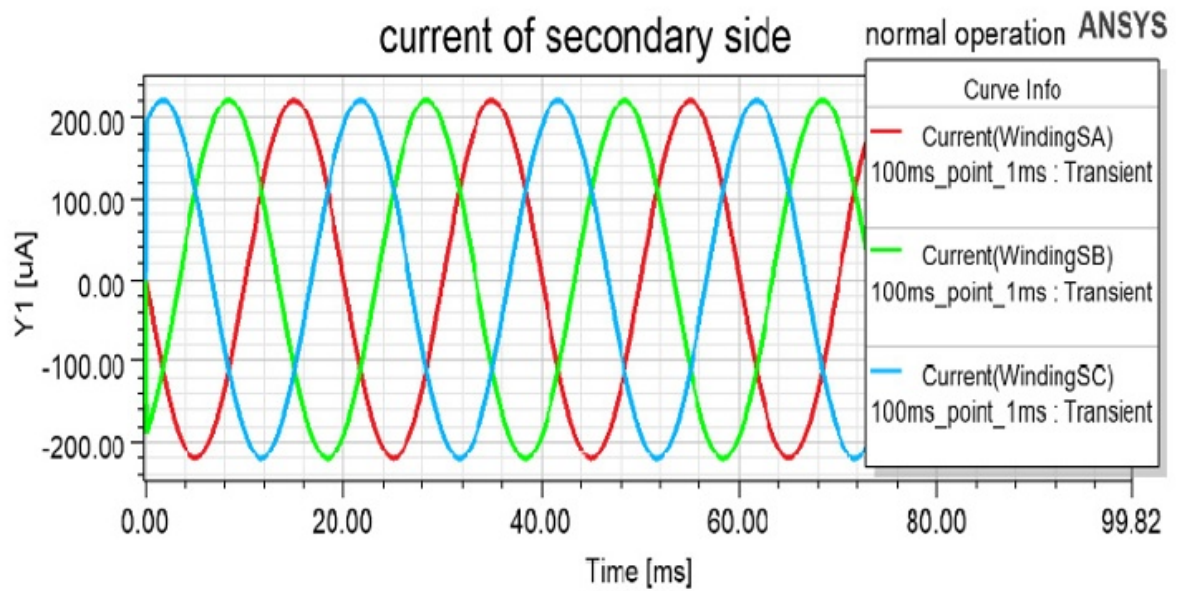

(d) The current of the secondary side.

Figure 12: Normal Operation 


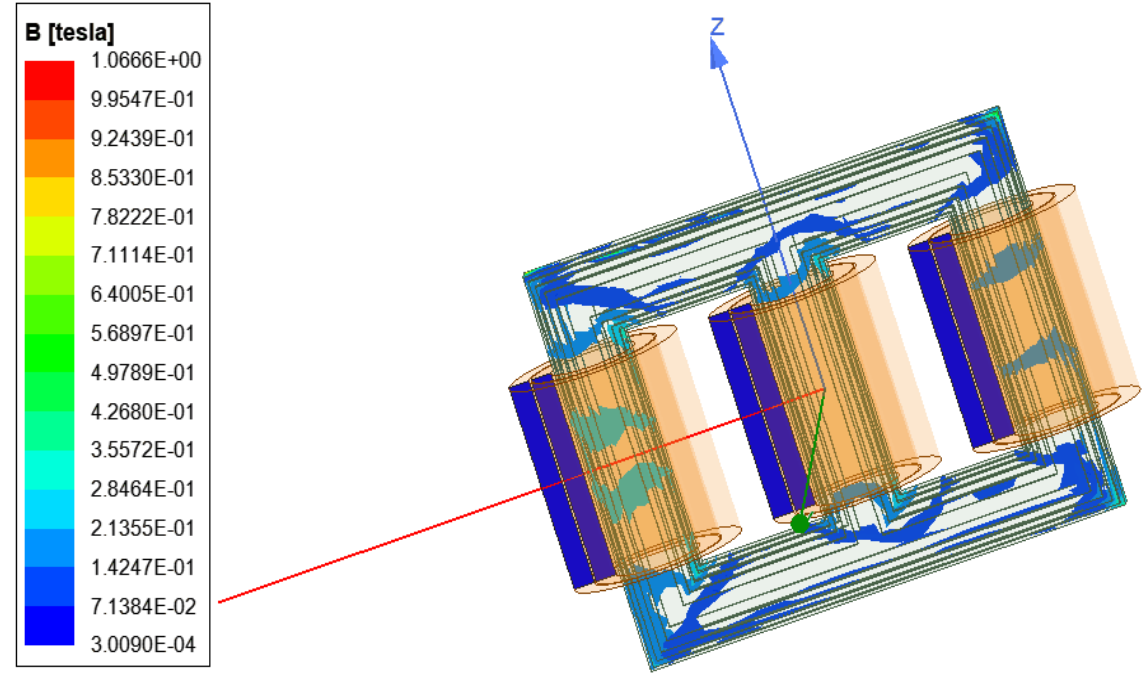

(a) DC Voltage $=5 \mathrm{~V}$

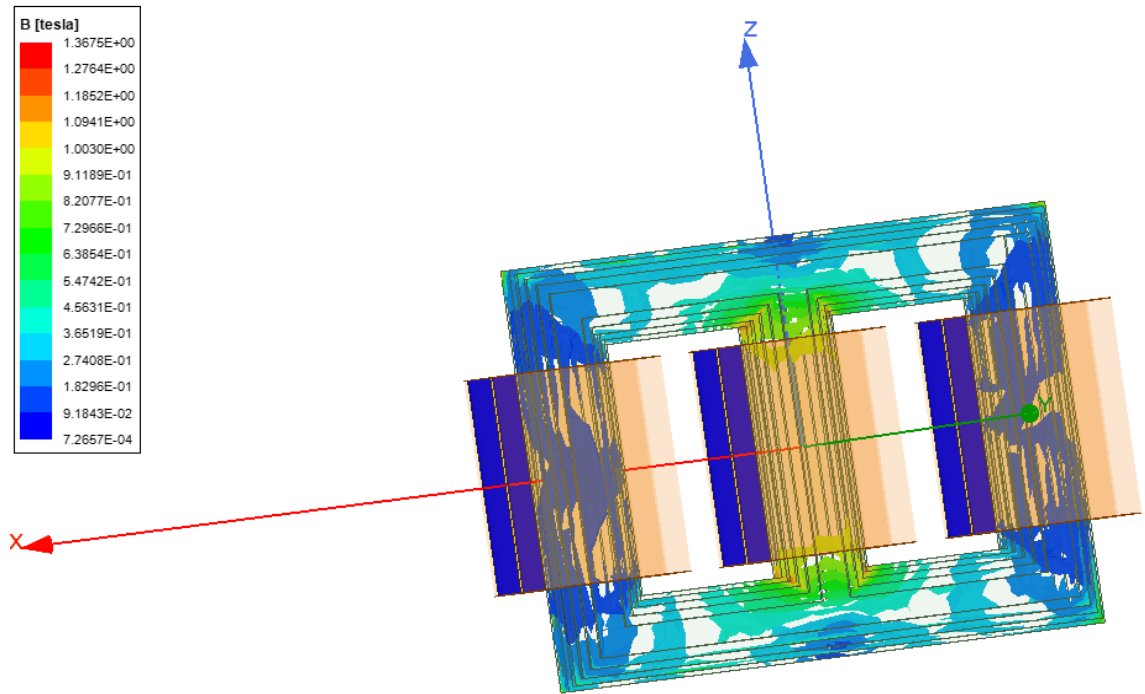

(b) DC Voltage $=10 \mathrm{~V}$

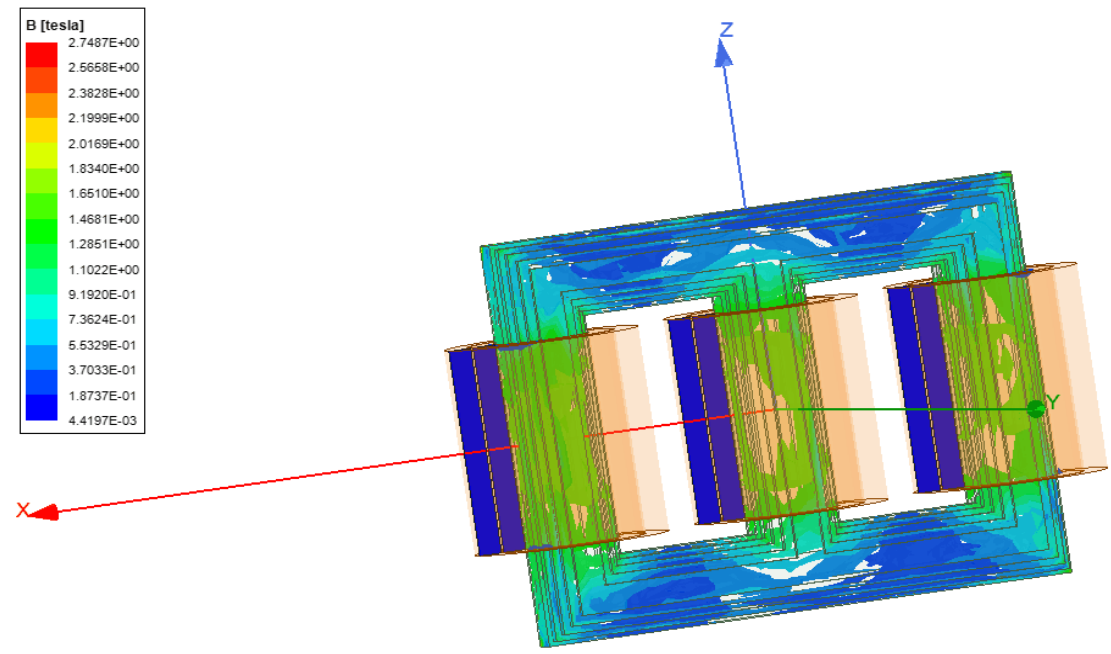

(c) DC Voltage $=40 \mathrm{~V}$

Figure 13: The Magnitude Density Distribution 


\section{Conclusion and Discussion}

This article briefly explained the background knowledge of the HVDC transmission system and summarized its structure and function. This essay explained how the 12pulse rectifier bridge circuit uses the transformer wiring structure to reduce the harmonics of the system through calculation and analysis. And based on the $\pm 800 \mathrm{kV}$ HVDC system, the converter transformer's basic design requirements in the HVDC system, including the criteria of transformer core, winding, cooling device, shortcircuit impedance, have been introduced. Finally, the DC bias phenomenon has been analyzed by MATLAB and ANSYS Maxwell, respectively. The simulation that aimed at the no-load simplified circuit model of the special transformer has explored the influence of DC bias on the converter transformer and HVDC transmission system. It concludes that when the DC component is added to the transformer, the excitation current waveform is distorted due to the transformer's core (magnetic flux) saturation and will appear sharps. The larger the DC component injecting, the more serious the excitation current distortion. However, to give a relatively rounded analysis, this article has ignored some aspects compared to the actual situation in the ANSYS Maxwell parameter settings.

\section{References}

1. M. Barnes, D. V. Hertem, S. P. Teeuwsen, and M. Callavik, "HVDC Systems in Smart Grids," Proceedings of the IEEE, vol. 105, no. 11, pp. 20822098, 2017, doi: 10.1109/JPROC.2017.2672879.

2. K. Eckholz and P. Heinzig, "HVDC-transformers-a technical challenge," in Proceedings. International Conference on Power System Technology, 13-17 Oct. 2002 2002, vol. 1, pp. 547-551 vol.1, doi: 10.1109/ICPST.2002.1053602.

3. W. z. Y.sun, J.Yang, N.Wang,Y.Lu, H.Li, "Hybrid DC Transmission Technology and Development Analysis," Automation of Electrical Power Systems, vol. 41, no. 7, pp. 156-167, 2017, doi: 10.7500/AEPS20161117005.

4. P. Sun, H. R. Wickramasinghe, and G. Konstantinou, "Hybrid LCC-AAC HVDC transmission system," Electric Power Systems Research, vol. 192, p. 106910, 2021/03/01/ 2021, doi: https://doi.org/10.1016/j.epsr.2020.106910.

5. A. Kumar, S. Jhampati, and R. Suri, "HVDC Converter Stations Design for LCC Based HVDC Transmission System-Key Consideration," in 2017 14th IEEE India Council International Conference (INDICON), 15-17 Dec. 2017 2017, pp. 1-6, doi: 10.1109/INDICON.2017.8487576.

6. Y. Liu, G. Li, L. Guan, and Z. Li, "The singleactive-part structure of the UHVDC converter transformer with the UHVAC power grid," CSEE Journal of Power and Energy Systems, vol. 3, no. 3, pp. 243-252, 2017, doi:

10.17775/CSEEJPES.2016.00580.

7. Y. Shuai, X. Han, L. Zhang, C. Yang, X. Hu, and H. $\mathrm{Wu}$, "Major insulation design consideration of converter transformer," in 2016 International Conference on Condition Monitoring and Diagnosis (CMD), 25-28 Sept. 2016 2016, pp. 1004-1007, doi: 10.1109/CMD.2016.7757996.

8. W. Feng and W. Chunning, "Parameters' calculation for converter transformer in HVDC system," in 2014 China International Conference on Electricity Distribution (CICED), 23-26 Sept. 2014 2014, pp. 26-29, doi: 10.1109/CICED.2014.6991656.

9. J. A. C. Forrest, "Harmonic load losses in HVDC converter transformers," IEEE Transactions on Power Delivery, vol. 6, no. 1, pp. 153-157, 1991, doi: 10.1109/61.103734.

10. Y. Wang, W. Zhang, J. Wang, D. Xia, P. Zhang, and J. Li, "Stray Loss Calculation of HVDC Converter Transformer," IEEE Transactions on Applied Superconductivity, vol. 22, no. 3, pp. 55006045500604, 2012, doi: 10.1109/TASC.2011.2174816.

11. M. V. Czernorucki, M. B. C. Salles, A. S. Melo, E. C. M. d. Costa, and L. Piegari, "Effects of the HVDC System on Converter Transformers," in 2019 8th International Conference on Renewable Energy Research and Applications (ICRERA), 3-6 Nov. 2019 2019, pp. 623-630, doi: 10.1109/ICRERA47325.2019.8997095.

12. C. Liu, M. Jin, H. Tian, X. Zhou, Y. Zhao, and W. Chen, "Converter transformer vibration analysis for $\pm 800 \mathrm{KV}$ Fengxian HVDC substation," in 2016 IEEE International Conference on High Voltage Engineering and Application (ICHVE), 19-22 Sept. 2016 2016, pp. 1-3, doi: 10.1109/ICHVE.2016.7800862.

13. P. Shao, L. Luo, Y. Li, and C. Rehtanz, "Electromagnetic Vibration Analysis of the Winding of a New HVDC Converter Transformer," IEEE Transactions on Power Delivery, vol. 27, no. 1, pp. 123-130, 2012, doi: 10.1109/TPWRD.2011.2174164

14. Y. Chen, Y. Li, Y. Peng, and L. Luo, "Vibration modal analysis and calculation of a new HVDC converter transformer with inductive filtering method," in 2015 5th International Conference on Electric Utility Deregulation and Restructuring and Power Technologies (DRPT), 26-29 Nov. 2015 2015, pp. 1683-1688, doi: 10.1109/DRPT.2015.7432522.

15. G. Bhuvaneswari and B. C. Mahanta, "Analysis of Converter Transformer Failure in HVDC Systems and Possible Solutions," IEEE Transactions on Power Delivery, vol. 24, no. 2, pp. 814-821, 2009, doi: 10.1109/TPWRD.2009.2014271.

16. S.Zhu, "Analysis and Treatment of Large DC Bias Power Transformer," Master, Shandong University of Technology 10433, 2019.

17. Q.Xiao, "Research on DC Bias Caused by UHV DC Transmission," presented at the Annual Meeting of 
Jiangxi Electrical Engineering Institution Nanchang City, 2018.

18. Y. Li, L. Luo, C. Rehtanz, C. Wang, and S. Ruberg, "Simulation of the Electromagnetic Response Characteristic of an Inductively Filtered HVDC Converter Transformer Using Field-Circuit Coupling," IEEE Transactions on Industrial Electronics, vol. 59, no. 11, pp. 4020-4031, 2012, doi: 10.1109/TIE.2011.2175673.

19. W. Sun, L. Yang, J. Hao, and F. Zare, "3D Electric Field Simulation of Converter Transformer with Real Insulation Materials Utilized in HVDC Systems," in 2018 IEEE International Conference on High Voltage Engineering and Application (ICHVE), 10-13 Sept. 2018 2018, pp. 1-4, doi: 10.1109/ICHVE.2018.8642072. 